\title{
PSIU - \\ PROJETO DE SERVIÇOS E INFORMAÇÕES \\ UTILITARIAS - RELATO DE UMA EXPERIÊNCIA \\ NA BIBLIOTECA PÚBLICA MUNICIPAL DE \\ LONDRINA (PR)
}

\section{Célia Regina Zambaldi Gléria \\ Norberto Alves Filho}

\begin{abstract}
Resumo
Apresenta o funcionamento de uma experiência acerca de informação utilitária em biblioteca pública existente na Biblioteca Pública Municipal de Londrina, Estado do Paraná. O serviço denominado PSIU - Projeto de Serviços e Informações Utilitárias - foi implantado em 1994 e vem se consolidando junto à comunidade usuária com a proposta de centralizar e oferecer informações através de uma base de dados sobre assuntos como: Turismo, Cultura, Utilidade Pública, Biblioteca Pública e sobre a Cidade de Londrina, apresentando sua história, serviços e potencialidade. $\mathrm{O}$ atendimento pode ser feito pessoalmente na Biblioteca, via fax, telefone (Disque PSIU) e Internet e tem constatado a facilidade de acesso à informação, dando chance ao cidadão, de obter benefícios sociais e culturais.
\end{abstract}

\section{Palavras-chave}

PSIU - Projeto de Serviços e Informações Utilitárias; Informação Utilitária; Biblioteca Pública; Internet.

\section{INTRODUÇÃO / JUSTIFICATIVA}

Situada no norte do Estado do Paraná, Londrina é uma cidade com 63 anos de idade e uma população de aproximadamente 500 mil habitantes. Seu crescimento verti- ginoso teve por base, inicialmente, a agricultura (que a tornou conhecida como a "Capital do Café") e hoje, apesar da pouca idade, ostenta ares de metrópole, sendo conhecida como a "Capital do Norte do Paraná".

A cidade conta atualmente com uma 
estrutura na área de prestação de serviços que influencia direta e indiretamente cerca de 230 municípios, os quais utilizam notadamente os serviços médico-hospitalares e educacionais do município.

Anualmente, Londrina recebe um grande número de pessoas vindas de vários estados do país e do exterior, as quais participam de eventos na cidade como a "Exposição Agropecuária e Industrial", concursos vestibulares, festivais culturais como os de música e teatro, congressos, campeonatos esportivos, festas, shows e demais acontecimentos que atraem um público diversificado.

A dificuldade para obter informações era uma constante em qualquer dos públicos, e até para a população residente que, mesmo após percorrer diversos caminhos, nem sempre encontrava a informação desejada.

Preocupada com a realidade apresentada e ciente de seu papel informativo e social, a Biblioteca Pública Municipal de Londrina reuniu informações sobre a cidade para compor uma base de dados que garantisse um atendimento rápido e eficaz ao público visando sanar a carência de informações. O serviço foi denominado PSIU - Projeto de Serviços e Informações Utilitárias e sua implantação ocorreu em 1994, concentrando informações sobre utilidade pública, cultura, lazer, serviços e dados estatísticos sobre a Cidade.
A experiência trouxe resultados positivos sob vários aspectos, como, por exemplo, a diversificação dos serviços da biblioteca, ampliando seu raio de abrangência a ponto de atingir uma nova clientela, consolidando a instituição como verdadeira prestadora do serviço de informações.

A seguir, serão apresentados maiores detalhes sobre a evolução e o funcionamento deste serviço.

\section{CARACTERIZAÇÃO DA INSTITUIÇÃO}

A Biblioteca Pública Municipal de Londrina foi criada pelo Decreto Lei no 78 , de 23 de novembro de 1940 e instalada em 04 de setembro de 1951.

Está ligada administrativamente à Prefeitura Municipal de Londrina através da Secretaria Municipal de Cultura.

Funciona desde 1984 em sua sede atual (antigo fórum de Londrina) localizado na área central e ocupa uma área de $1.972,47 \mathrm{~m}^{2}$. Possui um acervo de 170.000 volumes distribuídos no prédio central, 01 biblioteca infantil, 01 biblioteca ramal localizada na vila nova, próximo ao centro, 49 bibliotecas sucursais situadas em escolas da rede municipal e 08 caixas estantes que atendem escolas e instituições da cidade.

A freqüência diária da Biblioteca no prédio central é de 2000 usuários em média - com cerca de 1900 empréstimos 
mensais - que têm à sua disposição as seguintes opções: livros didáticos, obras de referência, literatura, periódicos (hemeroteca), obras referentes à história de Londrina, gibis e Coleção Nishinomiya (obras em japonês doadas pela cidade de Nishinomiya - Japão). A Biblioteca oferece ainda espaço lúdico (jogo de damas e xadrez), mural de eventos, mural de empregos, acesso à base dados do Sebrae e informações utilitárias através do PSIU. Estão sendo instalados terminais de acesso à Internet para o público, implantada uma audioteca e iniciado o processo de automação da Biblioteca.

O perfil do usuário, que consistia em sua maioria de alunos de $1^{\circ}$ e $2^{\circ}$ graus e universitários, tem-se modificado gradativamente devido à implantação de novos serviços, atraindo uma clientela diversificada, como profissionais liberais, de comunicação, artistas, empresários, promotores de eventos, agentes de turismo, donas de casa, professores, pais e pessoas à procura de emprego.

\section{A INFORMAÇÃO UTILITÁRIA E SUA IMPORTÂNCIA}

Segundo Figueiredo (1), a biblioteca pública possui algumas funções básicas, entre as quais a conservação dos registros gravados, auto-educação, estímulo à leitura e difusão ativa da informação. Além de manter essas funções a biblioteca pode evoluir para novas funções de caráter utili- tário, estendendo seus serviços a pessoas com acesso limitado às fontes, as quais podem auxiliar na solução de problemas do dia-a-dia.

A autora reforça que a realização desta tarefa comprova o papel social da biblioteca pública, em uma sociedade em constante transformação. Atender o anseio da comunidade no que diz respeito às suas necessidades informacionais é uma forma de a biblioteca manter-se atenta às transformações políticas e sociais, atuando como um organismo vivo que acompanha essa evolução.

Ao prestar esse serviço, passaria a servir não apenas aos indivíduos alfabetizados da classe média e estudantes que a procuram, mas a uma grande massa que não tem conhecimento sequer do que seja uma biblioteca, para os quais a informação passa a ter um significado real, o alcance de uma solução, a obtenção de um benefício social.

A proposta de trabalho do PSIU vai ao encontro dos conceitos apresentados. A idéia da implantação surgiu após constatação da ausência de um serviço que concentrasse informações sobre utilidade pública, cultura, lazer e serviços de forma rápida e dinâmica para atender à comunidade londrinense e visitantes ou turistas.

Assim o Projeto atende as mais variadas faixas de público, de todas as classes sociais, incluídas aqueles de menor poder 
aquisitivo e com dificuldades para obtenção de informações.

\section{O PSIU COMO NÚCLEO DE INFORMA- ÇÃO PÚBLICA}

\subsection{Objetivos}

\subsubsection{Objetivo Geral}

Atender a comunidade oferecendo informações sobre utilidade pública, história, turismo, cultura, lazer, serviços e potencialidades do município

\subsubsection{Objetivos específicos}

- centralizar informações para a comunidade, oferecendo informações de caráter utilitário, pessoalmente, via telefone, fax, correio ou internet;

- fornecer informações sobre serviços prestados por instituições públicas e privadas que possam ser de interesse da população;

- fazer cumprir o papel da biblioteca pública, através deste projeto, dentro do processo de democratização e transferência da informação;

- centralizar e divulgar informações sobre os eventos que estarão acontecendo no

\subsection{Informações}

O banco de dados do PSIU é composto por cerca de 12.000 informações, que se subdividem entre os seguintes assuntos principais:

- TURISMO - Nomes, endereços, telefone, URL e e-mail de hotéis, restaurantes e pontos turísticos de Londrina, entre outras informações ligadas ao tema;

- CULTURA - Agenda de eventos e opções culturais (teatros, museus, bibliotecas etc.), programação de cinema e informações sobre órgãos e entidades ligadas à cultura,

- UTILIDADE PÚBLICA - obtenção de documentos, localização e atribuições de órgãos públicos, serviços de saúde, segurança, comunicação, cursos profissionalizantes, entidades assistenciais, serviços 24 horas, locadoras de veículos, relação de autoridades etc.;

- BIBLIOTECA PÚBLICA - funciona- 
mento, serviços prestados, indicadores econômicos;

- LONDRINA - histórico e perfil atual (textos, fotos e dados estatísticos).

Foi criado um arquivo denominado Árvore de Assuntos, que contém todos os itens e subitens dos dados existentes no computador. Este arquivo facilita a busca tanto por parte do usuário quanto do operador, os quais podem encontrar rapidamente todas as informações disponíveis ou ter delas conhecimento.

Os assuntos podem sofrer alterações conforme a necessidade do público, ou seja, podem ser mantidos ou acrescentados novos grupos de informações.

\section{Árvore de Assuntos}

PSIU

\section{Turismo}

- Agências de Turismo

- Hospedagem

- Hotéis

- Pensionatos

- Estâncias

- Flats

- Apart Hotéis

- Pousadas

- Alimentação

- Pontos Turísticos

- Lugares Interessantes
- Casa de Show / Bares

- Fotos de Londrina

\section{Cultura e Lazer}

- Agenda Cultural

- Agenda da Semana

- Opções Culturais

- Cinemas

- Teatros

- Bibliotecas, Audiotecas, Videotecas...

- Museus

- Centros e Espaços Culturais

- Salas de Exposições

- Galerias de Arte

- Esporte

- Estádios, Campos...

- Órgãos Ligados ao Esporte

- Outros

Utilidade Pública

- Assistência Social

- Pública

- Privada

- Entidades

- Grupos de Apoio / Recuperação

- Clubes de Serviço

- Rotary

- Lyons

- Escotismo

- Sociedades

- Associações

- Apoio ao Trabalho

- Projetos Públicos

- Sindicatos

- Agências de Empregos

- Documentos 
- Saúde

- Hospitais

- Ambulâncias (192)

- Postos de Saúde

- Laboratórios

- Farmácias

- S.U.S.

- Clínicas

- Educação

- $1^{\circ} \mathrm{grau}$

- $2^{\circ}$ grau

- $3^{\circ}$ grau

- Cursinhos

- Profissionalizantes

- Transporte

- Segurança

- Comunicação

- Alimentação / Abastecimento

- Telefones Úteis

- Órgãos Municipais

- Órgãos Estaduais

- Órgãos Federais

- Embaixadas / Consulados

- Informações Político-Eleitorais

- Autoridades Federais

- Autoridades Estaduais

- Autoridades Municipais

- Autoridades ao longo da História

- Partidos Políticos

- Religião

- Cristianismo

- Budismo

- Islamismo

- Outras

\section{Londrina em Dados}

- Coordenadas Geopolíticas
- População

- Agricultura

- Esportes

- Orçamento

- Indústria

- Comércio e Serviços

- Comunicação e Lazer

- Divisão Administrativa

\section{Nossa Cidade}

- História

- Divisão administrativa

- Brasão de Londrina

- Bandeira de Londrina

\section{Hot Sites}

\section{Biblioteca Pública}

- Histórico

- Objetivos

- Estrutura

- Acervo

- Empréstimo

- Periódicos

- Difusão Cultural

- Estante Londrina

- Sucursais

- Biblioteca Infanto-juvenil

- Instalações

- Serviços

- Serviços de Circulação

- Referência

- Seção Periódicos

- Biblioteca Infantil

- PSIU - Projeto de Serviços e Informações Utilitárias

- Home Page da Cidade de Londrina 
- Mural de Empregos

- Clientela

- Biblioteca Ramal Vila Nova

\section{Museu de Artes de Londrina}

- História

- Objetivos

- Acervo

- Agenda

- Londrina

- Links

\section{3 Software}

O programa PSIU foi desenvolvido na linguagem clipper em parceria com uma empresa da área de informática em troca de publicidade. A estrutura era composta por duas opções de tela, endereço (cadastro) e texto - ambas com um campo para identificação do assunto. O programa foi apresentando problemas à medida que aumentava a quantidade de informações inseridas, além de não permitir alterações na sua estrutura pelo operador.

Como medida paliativa para facilitar a obtenção das informações solicitadas pelo usuário e melhorar a qualidade final do serviço até que se realizassem ajustes no programa, foram instalados os programas Microsoft ${ }^{\circledR}$ Windows $^{\circledR}$ (versão 3.11) e Microsoft $^{\circledR}$ Word $^{\circledR}$ (versão 6.0). Em seguida, o PSIU procurou, na medida do possível, manter os programas atualizados e compatíveis com a necessidade do usuário. Foram produzidos novos textos com imagens para que o público pudesse co- nhecer e visualizar pontos de turismo e lazer da cidade. Foi adotada a linguagem de hipertexto, cujos recursos permitiram a criação de uma home page sobre a cidade de Londrina.

\section{Criação da home page da Cidade de} Londrina - Vários usuários da rede Internet ${ }^{*}$ solicitaram informações sobre a cidade de Londrina ao webmaster da Sercomtel (servidor local). Visando atendêlos e também divulgar a cidade de Londrina e o PSIU, foi desenvolvida uma home page pela equipe do Projeto, a qual foi hospedada no servidor da Sercomtel, através de um convênio entre a empresa e a Secretaria Municipal de Cultura. Para tanto, as informações contidas no computador do PSIU e diversas outras disponíveis na sede do projeto foram enriquecidas com fotos e textos atualizados, criando uma nova interface. Em 25 de outubro de 1996, aconteceu o lançamento da home page da cidade de Londrina, na Biblioteca Pública Municipal, passo decisivo para consolidação do serviço, ampliando o atendimento em nível mundial.

Em agosto de 1997 foram inseridas novas páginas desenvolvidas e administradas também pela equipe do PSIU, sendo Projeto PSIU, Biblioteca Pública Municipal de Londrina, Biblioteca Ramal Vila Nova e Museu de Artes de Londrina.

* O acesso à Internet em Londrina começou em 1996. Nos meses de junho e julho a página foi elaborada, e em 25 de outubro do mesmo ano foi lançada oficialmente. 
PSIU on Line - A equipe do PSIU transferiu todo o conteúdo útil do programa utilizado no início do funcionamento para o formato HTML, para ser lido pelos browsers - navegadores - da Internet, de modo que tornou dinâmica a atualização e renovou a apresentação das informações, aproveitando os recursos da rede. Com essa transferência, todas as informações do PSIU disponíveis no computador foram para a Internet, podendo ser consultadas por qualquer usuário da rede no mundo*.

\subsection{Funcionamento da Experiência}

$\mathrm{Na}$ implantação, uma base de dados foi criada e inserida em um microcomputador. Foi instalada uma linha telefônica (número 300-1996 / Disque PSIU) composta por 02 terminais com busca automática para atender o usuário rapidamente, tanto por telefone quanto pessoalmente. Além do atendimento no local, desde o início, estava prevista a descentralização do serviço para locais de grande circulação de pessoas.

A sede do projeto funciona no prédio da Biblioteca Pública Municipal. $O$ atendi-

\footnotetext{
* Desde a implantação da Internet notou-se o recebimento de, em média, pelo menos um e-mail por dia e cerca de 60 acessos diários à página, até mesmo aos domingos e feriados (depois da implantação do $P S I U$ on Line os acessos diários passaram a cerca de 85), o que demonstra a importância do serviço na rede, já que muitas correspondências eletrônicas pedem informações relativas ao PSIU on Line, não somente da home page de Londrina.
}

mento é prestado pessoalmente na sede, através de telefone, fax, correios, e-mail e visitas à home page hospedada na internet.

A equipe do PSIU é composta por 03 funcionários em regime de revezamento, sendo 01 bibliotecário e 02 agentes de biblioteca com treinamento para o atendimento ao usuário, conhecimento de informática e interesse pelas informações prestadas pelo serviço.

Ao solicitar uma informação que não esteja disponível ou que seja extensa (por exemplo, agenda cultural de um mês todo), o usuário tem o seu telefone ou endereço anotado e recebe a informação posteriormente, após um contato feito pela equipe do projeto. Outro procedimento é a negociação quanto ao prazo para entrega das informações solicitadas.

É comum o recebimento de correspondências das mais diversas partes do país solicitando informações sobre a cidade, as quais são reunidas pelo PSIU e encaminhadas ao solicitante através da Secretaria da Cultura. São recebidos ainda vários e-mails de diversas localidades do país e do mundo, os quais são respondidos imediatamente ou encaminhados para outros setores ou mesmo órgãos que se encarregam de prestar as informações solicitadas ${ }^{* *}$.

\footnotetext{
** Podemos citar como exemplo alguns e-mails recebidos e encaminhados para o IPPUL — Instituto de Pesquisa e Planejamento Urbano de Londrina relativos ao trânsito e um outro encaminhado para a Junta Comercial do Estado do Paraná, solicitando informações.
} 
Periodicamente são enviados fax com o calendário de eventos para empresas cadastradas no PSIU, como emissoras de rádio, de televisão e jornais, revistas e boletins locais, bem como para empresas que desejam participar ou mesmo promover algum evento. $\mathrm{O}$ cadastro é feito através de ofício discriminando a periodicidade no envio das informações*.

Eventualmente são realizados levantamentos de dados solicitados por empresas, grupos musicais ${ }^{* *}$, órgãos públicos que têm intenção de obter um perfil histórico, turístico e socioeconômico da cidade.

A sistemática para obtenção das informações que compõem o banco de dados é feita mediante contatos com instituições públicas e privadas solicitando as informações, bem como através de pesquisas realizadas pela equipe responsável. Para inclusão de eventos é solicitado o preenchimento de um formulário específico distribuído pela equipe, os quais podem ser entregues preenchidos na sede do projeto, através de fax ou e-mail. O promotor do evento pode também solicitar sua inclusão simplesmente enviando folders ou cartazes alusivos ao evento.

\footnotetext{
" Com a aquisição de uma placa de fax/modem, em fevereiro deste ano, a atualização das home-pages tornou-se fácil e rápida e a transmissão de informações via fax passou a ser mais fácil e prática.

"Durante a Exposição Agropecuária e Industrial de Londrina de 1996, um grupo musical solicitou, de Porto Alegre, informações gerais e turísticas sobre a cidade, já que eles viriam para tocar e aproveitariam para passear pela nossa Cidade.
}

Após a instalação da home page da cidade de Londrina foi possível maior interação com o usuário, bem como maior facilidade para obtenção das informações através do acesso a outros sites da rede mundial.

A divulgação do serviço é feita através dos meios de comunicação, internet, cartazes, folders, publicação, durante o atendimento e através da publicação e distribuição semanal da Agenda Cultural do PSIU em locais de grande circulação, procurando atingir todos os segmentos da sociedade. Outra forma de tornar o PSIU conhecido é através de publicações em guias locais de telefones e endereços ${ }^{* * *}$ e participação em eventos.

\subsection{Indicadores Quantitativos e Qualita- tivos}

O PSIU mantém um sistema de estatística diária, através de impresso próprio que possibilita efetuar análises quanto ao uso do serviço. A metodologia permite recuperar dados referentes aos assuntos mais solicitados, além de produzir estatísticas mensais e anuais, bem como relatórios mensais minuciosos.

\footnotetext{
*** Em 1996, além da divulgação do número 3001996 - Disque PSIU na seção telefones úteis, foi desenvolvido um trabalho com informações gerais sobre Londrina (mapa, opções de turismo e dados sobre a cidade) pela equipe do PSIU e publicado nas 08 páginas iniciais do Guia Aqui Londrina 97 perfazendo um total de 128.000 exemplares.
} 
As anotações são feitas após o atendimento conforme o número de informações prestadas sobre cada assunto. Quanto ao controle de acesso à home page, foi instalado um contador que permite obter automaticamente o número de visitas às páginas. É controlado também o número de emails enviados diariamente - em resposta aos recebidos os quais são respondidos imediatamente ou encaminhados para outros setores.

Número de informações prestadas desde a implantação do PSIU:

O controle quantitativo no PSIU é uti- lizado para conhecimento do número de informações prestadas, e de crescimento e como forma de comprovar a validade do Projeto.

A tabela abaixo apresenta um resumo de todos os atendimentos ao longo dos quatro anos de funcionamento.

\section{FUTURAS EXPANSÕES}

Em virtude da velocidade das mudanças na área da informação e considerando que projetos da natureza do PSIU dispõem de recursos sempre limitados, as previsões para o futuro do serviço giram em torno de

\begin{tabular}{|c|c|c|c|c|c|c|}
\hline & 1994 & 1995 & 1996 & 1997 & 1998 & TOTAL \\
\hline TURISMO & 64 & 812 & 727 & 1452 & 229 & 3284 \\
\hline CULTURA & 156 & 8183 & 12719 & 20366 & 5198 & 46622 \\
\hline U. PÚBLICA & 525 & 2391 & 1950 & 3436 & 1764 & 10066 \\
\hline $\begin{array}{l}\text { ASSIST. } \\
\text { SOCIAL }\end{array}$ & 20 & 207 & 135 & 274 & 25 & 661 \\
\hline $\begin{array}{l}\text { APOIO AO } \\
\text { TRABALHO }\end{array}$ & 81 & 1224 & 930 & 849 & 332 & 3416 \\
\hline $\begin{array}{l}\text { BIBLIOTECA } \\
\text { PÚBLICA }\end{array}$ & 2235 & 5958 & 5150 & 4984 & 1164 & 19491 \\
\hline LONDRINA & 482 & 2229 & 2597 & 2956 & 141 & 8405 \\
\hline INTERNET & & & 4686 & 17283 & 6015 & 27984 \\
\hline E-M AIL & & & & 31 & 38 & 69 \\
\hline OUTROS & 202 & 4326 & 3584 & 6849 & 1801 & 19762 \\
\hline TOTAL & 3765 & 25330 & 32478 & 61480 & $16707^{*}$ & 139760 \\
\hline
\end{tabular}

* Até março de 1998. 
adaptações que possam garantir sua atualização (evolução tecnológica) de forma que o mesmo não corra o risco de tornar-se obsoleto em relação a seu objetivo, ou seja, prestar informações a todos os segmentos da sociedade.

Foram observados, no entanto, alguns aspectos, como:

- descentralização do serviço — disponibilização das informações contidas no PSIU em quiosques multimídia (obtidos através de convênios com empresas públicas e/ou privadas), para permitir o acesso em locais de grande circulação de pessoas (shoppings, terminais de passageiros, eventos, entre outros, localizados em Londrina);

- tradução dos textos disponíveis na rede para outros idiomas, como inglês e espanhol;

- elaboração do calendário de eventos conforme orientação do Ministério da Cultura - já em fase de apreciação e testes;

- realização de um estudo de usuário do serviço com o objetivo de obter um perfil para implementação de novas mudanças;

- busca de novos recursos da rede Internet, utilizando o acesso permitido pela rede interna da Prefeitura;
- busca de recursos através de parcerias com empresas em troca de publicidade no local ou internet (banner rotativo);

- manutenção de materiais impressos de boa qualidade para divulgação do PSIU junto a comunidade;

- maior envolvimento com todos os segmentos da sociedade para fortalecimento deste canal de informação.

\section{CONCLUSÃO}

As transformações na área da informação estão acontecendo em nível mundial e a globalização não é apenas econômica. O mundo passa por um processo de universalização, tanto da cultura quanto de outras áreas. A Internet é o assunto (e a ferramenta) do momento.

Para Sampaio (2), a Internet já faz parte da vida de muitas pessoas e o acesso à rede permite a realização de pesquisas, fechamento de negócios, comunicação com outras pessoas etc., sem que o usuário precise deslocar-se de seu endereço.

A realidade é que todos os segmentos da sociedade, visando lucro ou não, tendem a adaptar-se às mudanças para garantir maior competitividade, pois permanecer apenas nos meios convencionais pode significar perda sob vários aspectos.

Dentro desta perspectiva, o PSIU é um 
serviço que procura acompanhar as mudanças e após a criação da home page, as informações sobre Londrina passaram a fazer parte do cenário mundial, acompanhando o desenvolvimento crescente na área da informação ao mesmo tempo que procura atender às necessidades do usuário, seja este próximo do local ou distante.

Poucos municípios possuem serviços com características semelhantes ao PSIU, principalmente integrados ao funcionamento de uma instituição voltada para o cidadão como é o caso da biblioteca pública.

A experiência apresentada demonstra que é possível inovar serviços para garantir a continuidade da biblioteca pública mesmo diante de ameaças tecnológicas.

Pode-se constatar que o serviço aumentou a facilidade de acesso à informação e através dele a chance de o cidadão obter benefícios sociais e culturais.

\section{Referências Bibliográficas}

1 - FIGUEIREDO, Nice. Serviço de informação para a comunidade como instrumento de democratização da biblioteca pública brasileira. Rev. Bras. Biblioteconom. Doc., São Paulo, v. 18, n. 3/4, p. 7-19, jul./dez. 1985.

2 - SAMPAIO, Cleuton. Home page II sem traumas. 2.ed. Rio de Janeiro: Brasport, 1996. 137p. 


\section{Célia Regina Zambaldi Gléria}

Bibliotecária da Biblioteca Pública Municipal de Londrina.

\section{Norberto Alves Filho}

Da Biblioteca Pública Municipal de Londrina. Criador de home pages

\section{Title}

PSIU - Community Utilitarian Information Service: the Report of an Experience in the Public Library of Londrina (PR)

\section{Abstract}

This is a report about the experience in utilitarian information at the Public Library of Londrina, in the State of Paraná. The name of the service is PSIU (Projeto de Serviços e Informações Utilitárias) - Community Utilitarian Information Service. PSIU was created in 1994 aiming at centralizing and providing easier access to information in fields like Tourism, Culture, Employment, Public Utilities, the Public Library, and the city of Londrina, namely, its history, services, and potentiality. The service is available by means of facsimile, telephone, Internet, or by visiting the Public Library.

\section{Keywords}

PSIU - Community Utilitarian Information Service; Utilitarian Information; Public Library; Internet.

\section{Titulo}

PSIU - Proyecto de Servicios e Informaciones Utilitarias - Relato de una Experiencia en la Biblioteca Pública Municipal de Londrina (PR)

\section{Resumen}

Presenta el funcionamiento de una experiencia acerca de la información utilitaria en biblioteca pública existente en la Biblioteca Pública Municipal de Londrina, Paraná. El servicio denominado PSIU - Proyecto de Servicios e Informaciones Utilitarias - fue implementado en 1994 y se ha consolidado junto a la comunidad usuaria con la propuesta de centralizar y ofrecer informaciones a través de una base de datos sobre asuntos como: Turismo, Cultura, Utilidad Pública y sobre la Ciudad de Londrina, presentando su historia, servicios y potencialidad. La atención puede ser hecha personalmente en la biblioteca, por fax, teléfono ("Llame PSIU" ) e Internet y ha constatado la facilidad de acceso a la información, dando oportunidad al ciudadano de obtener beneficios sociales y culturales.

\section{Palabras Clave}

PSIU - Proyecto de Servicios e Informaciones Utilitarias; Información Utilitaria; Biblioteca Pública; Internet.

Artigo recebido em: 30/04/98 